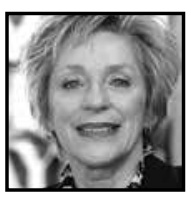

\title{
Regulating Early Childhood Mathematical Provision: An Exploration Across the Sectors
}

\author{
Margaret Walshaw, Massey University
}

\begin{abstract}
Effective mathematics provision is a central goal within Early Childhood Education. However, the choices that teachers make within Centers and new entrant classrooms are influenced by deeper understandings about the kinds of arrangements that allow young students to enhance their learning. This paper explores similarities and differences with respect to the practices and processes in Early Childhood Centers and in new entrant classrooms. Drawing on Foucauldian concepts, the analysis reports that practices and processes were at odds across the two sectors. The challenge is to offer young learners a more seamless mathematical experience.
\end{abstract}

\section{Introduction}

ffective mathematics provision that produces desirable student outcomes is the

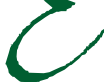
ultimate aim for every mathematics teacher. Whether based in a Center or in a school, teachers work towards understanding what students "need to learn and then challenging and supporting them to learn it well" (National Council of Teachers of Mathematics [NCTM], 2000, p. 16). However, in understanding what needs to be learnt and how that might be achieved, the ideological, structural, and organizational dimensions of mathematical provision come into play. These dimensions are all part of the large matrix of practice that involves wider systemic and policy support for teaching and learning. That is to say, the choices that a Center and school make include the negotiation of relevant mathematics curriculum policy and carry over to decisions about the human and material infrastructural arrangements that allow young students to achieve desirable outcomes. 
Decisions made at the Center level that are at odds with those made in new entrant (reception) classrooms have been shown to have a long-term impact on adjustment (Kienig, 2002) and on school achievement (Perry \& Dockett, 2004; Timperley, McNaughton, Howie, \& Robinson, 2003). If, as Neuman (2002) has suggested, impediments to smooth transitions between sectors are generated by different visions and cultures, then we want to have a clear idea about how Center and school personnel talk about their own and the other sector's practices. At a time when the policy machinery in New Zealand is focused on enhancing communication between sectors, we wanted to explore how the practices and processes at the Center, in relation to mathematics provision, correspond to the practices and processes in new entrant mathematics classrooms. Identifying school and Center patterns that contribute to seamless practice is important if we are to enhance our understanding of the relations between mathematical provision and the creation of young learners' mathematical identities.

The theoretical underpinning for this exploration on how teachers enhance young students' mathematical understanding can be found in the work of Foucault (e.g., 1977, 1984). The work proposes that what people may say and do is made available within discourses that are imbued with power. In relation to this study, the kind of mathematical provision that might be constructed in a Center or in a school is developed from situated, localized practices that, in turn, determine the spectrum of speech acts and actions that can be taken seriously at any given time. It is these practices and activities that contribute to how young students "think about themselves in relation to mathematics and the extent to which they have developed a commitment to, and have come to see value in, mathematics" (Cobb, Gresalfi, \& Hodge, 2009, pp. 40-41). Thus, such practices and activities and the visions, commitments, motivations, and capacities that underwrite them, are deeply implicated in the development of a quality mathematical experience.

In accounting for those practices that are operationalized by Center and school personnel, insights are offered in relation to the mathematical provision at four Centers and two schools. The discussion explores the mathematics pedagogy and the assessment practice privileged at the sites and includes parental perceptions. In utilizing concepts from Foucault's toolkit, the analysis draws particular attention to the differential enactment of practices, in the hope that conclusions about mathematical provision might be made. Since there are high costs in the perpetuation of differential practice between sectors (Kagan \& Neuman, 1998), the challenge is to find a way to negotiate those differences. 


\section{Conceptual Tools From Foucault}

The exploration into early childhood settings and new entrant classrooms begins with Foucault's theory of language and social power. Foucault (e.g., 1977, 1984) provides a framework that allows us to respond to the complex interplay between social structures and the processes of mathematical provision between two different sector levels that might be at work for young mathematics learners. These tools allow us to respond to the complex interplay between social structures and the processes of mathematical provision between two different sector levels that might be at work for young mathematics learners.

In Foucault's poststructuralism (e.g., 1977), discourses are of key interest. Rather than focusing on communication and speech, Foucault's understanding of discourse is centered on the taken-for-granted "rules" that specify what is possible to speak, do, and even think, at a particular time. Discourses, for him, refer to different ways of structuring areas of knowledge and social practice. Institutions, like early childhood settings and schools, demonstrate forms of social organization and social practices that may not be similar from one setting to another. They have particular approaches to mathematics pedagogy, parental expectations, assessment, and so forth. All these discursive practices have their place in creating mathematical provision for the teacher and the learner. That is to say, discourses surrounding the category "mathematical provision" provide teachers, learners, parents, and others with an understanding of how mathematics should be provided for and recognized. Because there are often different discourses at play between settings, the ways in which we understand mathematical provision in one educational site might be quite different from another site.

These discursive practices are immensely powerful, precisely because inherent within them is an implicit set of rules that governs beliefs about the ways in which mathematics provision might be understood and operationalized. The important point is that discourses do not merely reflect or represent mathematical provision; rather, they actively construct them. Power, then, is constituted in discursive practice. It is this Foucauldian idea that has far-reaching implications for understanding practices and processes in education. In relation to this study, power systematically creates versions of the mathematical world within early childhood education and school settings. It governs and regulates social interaction and infuses our understanding of "mathematical reality" in these particular sites. In Foucault's understanding, power not only produces the meanings that people make of mathematical provision, but it also sustains those meanings. Power normalizes thinking and acting to the extent that people in settings such as Centers and schools, tend to match their behavior against the taken-for-granted 
standards and established covert controls. Given that power is local, continuous, and present in the most apparently trivial details of life, then it will be useful to look at the micro-level of practice within the Center and the classroom to trace how mathematical provision is created and maintained in subtle and diffuse ways.

\section{Methodological Matters}

In applying Foucault's ideas to mathematical provision, I draw on data from a twoyear study that explored transition practices between four early childhood centers (ECC) and two new entrant (reception) classrooms in primary schools into which those four Early Childhood Education (ECE) settings feed. The four centers comprised two kindergartens and two early childhood education and care centers. Both kindergartens employed three teachers and 45 children aged from three years and nine months to five years (five years being the school entry age in New Zealand). Children attended the kindergartens each weekday from 9 a.m. to 12:30 p.m. In the two privately owned centers, both with three teachers/caregivers, 12-15 children were enrolled for a full day. The two schools in the study were similar in size and decile rating': School 1 was a decile-4 school consisting of 480 students. School 2 was a decile-3 school with a roll of 440 students. Both schools catered for new entrants in two classrooms and all four classrooms were involved in the study.

Data sources included observations within the ECE, teacher interviews, parent questionnaire, and documentation including teaching policies and student assessments at the ECC during the first year of the research. Similar data sources were collected at the school sites during the second year of the research. Questionnaire responses from 62 parents of children at the four Early Childhood Education settings and 46 parents of children at the two schools also contributed to the dataset. From the full dataset, and putting to use Foucault's concepts of discourse, power, and surveillance, conclusions were drawn about similarities and differences regarding mathematical provision at the respective educational sites. Thus, underwriting the research was a central question: What does mathematical provision look like in early childhood settings and new entrant school classrooms? Since the investigation was undertaken in specific localized sites, situated within a small town in New Zealand, generalization to other ECC and school environments is limited. However, the analysis points to some initial speculations about how mathematical provision might be offered in other ECC and new entrant settings. From the findings, inferences could then be made about the transition experience and the identities created in relation to mathematics for young students. 


\section{The Discursive Production of Mathematical Provision}

\section{The ECE Setting}

At the Early Childhood Centers, teachers position children in relation to the official policy statement Te Whäriki (Ministry of Education, 1996), and to the Center's interpretation of that policy, with respect to the teaching and learning of early childhood. At the school within the new entrant classroom, other discourses come to play which in some ways confirm and in other ways contradict the discourses promoted by the Center. I explored mathematics provision at the ECE settings by exploring the philosophies that underpin, and the infrastructural arrangements in place for, mathematics teaching and learning. In the following, words have been taken from teachers' and parents' responses:

"Children need to have autonomy of their learning and to be able to make some choices for themselves."

"The whole Te Whāriki is more of a holistic approach to children's learning. They will learn all those things in due course through stages of development, through their own interest-driven activities."

“It happens throughout the whole engaged curriculum. It doesn't stand as a solitary stand-alone exercise unless it is extending a child's interest. "

Within the learning environment of the ECE setting the teacher was required to observe, interact, challenge, scaffold, and co-construct mathematical knowledge. Children worked alone, in solitary play or in parallel play, or played together (see also Perry \& Dockett, 2011). Center teachers were watchful for opportunities to "step in" in order to progress children's understanding and interest. If a child showed a particular interest the teacher was expected to build on and nurture that interest, whilst maintaining a responsive and reciprocal relationship. On those occasions the teacher remained at the activity, encouraging and extending the learning through conversations and challenges. As some teachers remarked:

"Often it just kind of happens in that moment in the water trough or the sandpit or you use what is there at the time."

"So it is based around a child's interest and we can seize an opportunity and teachable moment and extend it. 
"Working with other children never just by themselves either. There would be a group of children invariably come along. You might start with one but you would end up inviting other children to participate and all the turn taking and the sharing."

The provision of opportunities for rich mathematical learning and language development was provided at the Center in areas such as the sand pit, block corner, family corner, water play, with farm animals, toy cars, carpentry, and computer games. More formal activities, such as shape matching, bead threading, puzzles, and jigsaws, were also available to enhance mathematical learning. One parent said,

"The first thing that came into my mind was the mathematical language that is used all around the centre in lots of different areas... you know the measuring, longer, shorter, longer...with the carpentry, water, sandpit. All of those words, classifying and sorting words."

Discourses operating within the Center relating to "rich mathematical learning" and "language development" are ways of giving meaning to the world. In Discipline and Punish, Foucault (1977) explains that power operates within discourses, like these, not overtly but, rather through its invisibility. These discourses are effective as normalizing forces because they are relatively invisible in their operation. That is, mathematical learning and language development are regulated through a set of standards and value systems which is created and maintained in subtle and diffuse ways. Of the 62 parents in the ECE component of the study, some believed that mathematics occurs "often" as children play with puzzles and games $(43 \%, n=27)$, during mat time $(45 \%$, $\mathrm{n}=28)$, at construction $(30 \%, \mathrm{n}=19)$, in water play $(29 \%, \mathrm{n}=18)$ and on the computer $(32 \%$, $\mathrm{n}=20$ ). Another teacher stated,

"We have a lot of parents that will come in and work with their children at the puzzles, at the play dough table, at one of our tables that we might have a game set up."

According to parents, mathematics teaching and learning takes place "sometimes" in the writing area $(34 \%, n=21)$, with play dough $(29 \%, n=18)$, and in the family corner $(32 \%, n=20)$. Parents believed that the ECE teachers work with children on aspects to do with mathematics "all the time" through conversations ( $32 \%, \mathrm{n}=20)$, and "often" during mat time [whole group time] $(49 \%, n=30)$, and with inside equipment $(43 \%, n=27)$. Through implicit discourses, in relation to the level of mathematics offered in the ECE setting, they had come to expect that mathematics would be "very basic."

"At [the ECE setting] children can wander from activity to activity." 
"At [the ECE setting] you are kind of aware of it [mathematics] in the background and notes are made in the children's profiles - that they [the children] had been seen to be counting."

Displays of children's work, routines such as roll taking utilizing category data and information-sharing charts for parents on learning and curriculum, also provided a mathematical focus within the early childhood setting. At the same time the routines also regulated minute details of space and time. Mat time [whole group time] often provided an opportunity for a mathematics focus. These occasions were initiated by the teacher or sparked by the teacher's observation of a child. As two of the ECE teachers noted:

"We definitely bring it [mathematics] out in planned times like that."

"I was working with a little boy who was going 123 and I thought there is a whole heap of stuff there... So that is why I thought of bringing in [at mat time] the actual 1 2 3...It's not giving him the knowledge; it's like developing an awareness."

Thus planning, aimed to enhance either individual or group mathematical understanding, was often informed by anecdotal assessments, made on the basis of teachers' observations of children's interests. The planned activities were offered to meet the needs and interests of the children. However, children were not required to carry out these activities.

"Planning for us can come from when we see an interest and then we bring in the resources. That would be in our session evaluation we would look at that and how we would extend it."

If the ECE context defined its own borders for teaching and learning, it also constructed its own understanding of assessment. Narrative assessments were the most common form of assessment within the ECC. These tended to document, in written and photographic form, the dispositions exhibited by the child rather than focus on a specific content area. The intent was to illustrate the ways in which a child was actively engaged in the learning environment rather than merely to report on the achievement of a skill (see Jordan, 2004). The narratives, describing the whole experience to ensure that the complexity of the learning was preserved (Carr, 2001), were set within a background that provided evidence of specific mathematical concepts being developed, practised, or achieved. Aimed at a broader audience, and inclusive of a range of voices, the narratives were typically stored in an individual child's portfolio as a Learning Story 
and were available at any time to teachers, children, and family. They offered a rounded view of the young student's mathematical engagement. For example:

"You enjoyed your time in the water, filling bottles, using jugs and small containers. You had really good concentration and showed awesome control when pouring the water into the bottles. You lined the new cylinders up from smallest to largest and filled these too. You were not only developing your fine motor control but discovering all about volume." (Learning Story)

"She just thrives on painting activities and creates wonderful pieces of artwork. It has been observed that $\mathrm{J}$. is very interested in painting circles. ... Mum explained to us that in the weekend J. was learning about the different shapes. This could link to why she has really enjoyed creating circles." (Learning Story)

"H. may have a strength with the number system. We will offer more resources to stimulate his interest." (Learning Story)

Teaching and learning mathematics in the ECE setting was mapped onto a complex grid of formal and informal educational discourses and practices. Teachers constructed their notions of mathematics teaching and learning through familiarity with policies and through their personal experiences of teaching. Working from an understanding that the child's informal mathematical knowledge was a building block for teaching and for learning, teachers were expected to build on the "child's current needs, strengths, and interests by allowing children choices and by encouraging them to take responsibility for their learning" (Ministry of Education, 1996, p. 20). The view was that numerical knowledge should be guided by the understanding that "to be numerate is to have the ability and inclination to use mathematics effectively in our lives, at home, at work, and in the community" (Ministry of Education, 2001, p. 1). Assessment should "[f]eedback to children on their learning and development [and] should enhance their sense of themselves as capable people and competent learners" (Ministry of Education, 1996, p. 30).

Theoretical decisions about teaching, learning, and assessment like these have important implications for the ways in which mathematics provision can be conceptualized and enacted (see Perry \& Dockett, 2011). In privileging the use of material resources, in recognizing prior knowledge and difference, in validating individual and group activities, integrated learning, play-based pedagogies, and narratives for assessment (Davies $\&$ Walker, 2008), a notion was formed of young children as steeped in the early-development phase of mathematics learning. Teachers were to assist that development by 
co-constructing knowledge with "as they engage[d]in meaning making" (Cullen, 2004, p. 70). By naming these categories, ECE teachers had established their own personal classificatory grid for the development of young learners within the setting.

In Foucauldian understanding, the ECE settings produced their own truths about mathematics provision. They operated with an established set of rules of formation, through a network of material and embodied relations. By advancing a specific ideological construction of mathematics teaching, learning, and assessment, and by producing mechanisms to shape the knowledges, modes of operating, and positionings of the teacher and the children, the ECE settings created the conditions for certain discourses and not others, about mathematics provision to be recognized. Foucault put it like this: "Every educational system is a political means of maintaining or modifying the appropriateness of discourses with the knowledge and power they bring with them" (Foucault, 1972, p. 46).

\section{New Entrant Classrooms}

Within the new entrant classroom, new aspects of the mathematical world were laid bare and new relationships with teachers and others in the learning community were made available. This new context also organized and strategized for time and space differently from the ECE setting. The approach to learning changed from a focus on personal, social, and emotional development to the formal beginning of mathematical content prescribed in the form of "achievement objectives" within the national curriculum (Stephenson \& Parsons, 2007). Typically, children were placed in ability grouping from their first day at school and experienced formal whole-class mat time, followed by group rotations. Similar to findings provided by Belcher (2006), mathematics was presented in a structured lesson format. Such lessons occurred at a regular time of the school day, and contrasted with the mathematical experience offered in the early childhood setting.

"I think there is an expectation of when they come, well, how they behave when they are at school and numeracy time is a set time."

"We have ability groups. We have two rotations. One rotation they see me and two they do an independent activity. That goes for four days a week and on the fifth day we have a maths circuit."

Like many educational practices, the typical lesson structures pedagogical arrangements for mathematical work, establishing a set of practices and social relations for the 
teacher and learner in the classroom. While the new entrant teachers expressed a belief in the importance of children learning through play, they did not reflect this in practice. As evidenced by classroom observations, in most classrooms, on the basis of ability grouping, the teacher introduced new concepts for the lesson to one group each day; provided explanations; modeled; posed questions for the children; supplied work and activities to enable practice of those mathematical ideas; and finally reflected on the work. In this logic the teacher moved reflexively from talk, to writing on the board, to observing, to talk and questioning, all the while grounding understanding through the process of children's activity and written work.

Practices of administration like these induce the mathematics learner in the new entrant classroom into a particular cyclic order in which specific tasks and functions, by turn, are to be performed. In Foucault's (1972) understanding, they “...lay down what must be related, in a particular discursive practice, for such and such an enunciation to be made, for such and such a concept to be used, for such and such a strategy to be organized" (p. 74). Because these institutional practices fix limits, controlling the "time" around which mathematical reality might take place, they foster the development and control of what is to count as the mathematical provision. Such organizational procedures sanction what Foucault (1977) calls "normalization."

It was through the rotations that opportunities for learning with others in a less structured teacher-driven learning setting were made possible. During non-contact teacher time within a lesson, a group of similar-ability children was provided with teacher-selected focused games or resources to stimulate self-generated activities.

"They [non-contact groups] will either be activities to reinforce previous learning or to help with current learning or a sheet [photocopied worksheet]. More formal type activity for counting. Something where they have got to record."

"That is where I have developmental type activities so they have a little bit of structure on the mat. Then they have freedom of other activities at the same time they are learning that rotation process."

"Yes, they are allowed to have free choice but not so much in maths time because I do prefer them to use more appropriate activities that tie in with what they have been learning."

However, similar to the findings made by Belcher (2006), children in the non-contact group tended to spend their time practising social and organizational skills, rather 
than developing mathematical knowledge. Although they had some control over their learning with respect to the selection of predetermined equipment, the children in the non-contact group had little opportunity to interact with the teacher.

Davies (2011) and Peters (2010) have argued that connections between the practices in place within the new entrant classroom and those found in the early childhood context are, at best, tenuous. Parents were mindful of this, believing that "maths learning" changed once the child started school. One third of the 46 parents involved in the study responded consistently across all options that they "did not know" where mathematics occurred within a new entrant classroom. Of the remaining parents, mathematics occurred "all the time" in the mathematics corner $(33 \%, \mathrm{n}=15)$ and in structured mathematics lessons $(33 \%, n=15)$ and "often" in puzzles and games $(36 \%, n=17)$. Construction, play dough, and the writing area were places were mathematics "sometimes" occurred. When asked how the teacher helped their child learn mathematics around $50 \%$, or approximately 230 parents "did not know," 21\% $(n=10)$ responded that teachers used a formal maths lesson "all the time" and "often used" conversation ( $25 \%, n=12)$, mat time $(25 \%, n=12)$, and formal lessons $(18 \%, n=8)$. These findings supported those of Belcher (2006) in that parents "were unaware of the extent of their children's shift as they moved from the holistic learning environment of the early childhood to the constructivist school environment where learning focused on achievement of prescribed objectives within separate curricula" (p. 114).

Although it has been suggested (e.g., Margetts, 2007) that new entrant teachers should be responsive in the early weeks of schooling to children's prior knowledge, little evidence of this was found. Parents, on the other hand, were well aware of the importance of informal knowledge and how they might help their children learn mathematics in everyday settings. However, only $25 \%$ of the parents could confirm that the new entrant teacher had acknowledged their child's prior mathematical understanding. Conversations at home $(68 \%, n=31)$ and daily routines $(46 \%, n=21)$ were "often used" together with play $(53 \%, n=24)$, computer games $(50 \%, n=23)$, conversations away from home $(46 \%, n=21)$, and published maths materials $(46 \%, n=21)$ "sometimes" to enhance their child's understanding.

From observations and planning documents, it is evident that mathematical provision in the classroom was teacher initiated with predetermined learning intentions. Lessons were planned by the teacher, rather than initiated through a child's needs or interests. Since teachers were preoccupied with "getting through" their planned instruction and sometimes distracted by issues of classroom management, they were unable (or unwilling) to scaffold or respond interactively to children's initiations. 
"Most of the mathematics we do will be from the numeracy project or activities off the NZ [New Zealand] website."

Like the findings provided by Young-Loveridge (2011), assessment practices at the school level were markedly different from those undertaken in the ECE setting. Indeed, both new entrant teachers and teachers within ECE settings had limited understanding of mathematics assessment as it was understood in the other environment (see also Sherley, Clark, \& Higgins, 2008). Often within the first few days of arrival at school, a young learner was assessed using official checklists or tools.

"We do observation assessment for the first six weeks and then in the sixth week we do the NUMPa Form A ... and after that we carry on with a tick chart, one from the numeracy project stage that they are at."

"I put this in the child's profile book with a link about the learning involved and I thought wouldn't this be great if I could hand it on to the teachers, so they had a knowledge of where they were at. But I don't know, maybe they have their own assessment." (Teacher ECE)

The new entrant teachers invested in their own particular discursive codes of mathematics pedagogy, which, in turn foregrounded particular processes and practices for assessment in the classroom. These were at odds with the discursive codes for pedagogy found in the early childhood setting and supported wider findings offered by Anthony and Walshaw (2009). However, it is not simply the classroom teacher who performs the normalizing function by stamping her own mode of practice upon the classroom: beyond the classroom, and as part of the wider educational process, the teacher, herself, is an object of what Foucault (1984) has named as surveillance from, among others, the school, from educational "inspectors," from curriculum policy makers, and from the wider community. In Foucauldian terms, assessing others is "a surveillance that makes it possible to qualify, to classify and to punish. It establishes over individuals a visibility through which one differentiates them and judges them" ( $p$. 184). The schools, "inspectors," and so forth, all perform the tasks of controlling, policing, and normalizing forms of classroom behavior. By way of example, in interview the new entrant teachers clarified that they relied heavily on a national student diagnostic interview as a means of determining a classification of children's achievement levels. The new entrant teachers often referred to "filling the gaps" of mathematical knowledge. These perceptions appeared to be formed from assessments that overlooked the competencies documented earlier within the narratives in the ECE settings. 
"So they come out at 0 [Stage 0 of Number framework]. So they don't know any of these things." (New entrant teacher)

Reporting practices on children's progress were consistent in both schools. Both schools completed an oral and written report at six weeks in relation to how the child had settled and the progress the child was making. Parents reported they sometimes the spoke to the teacher informally regarding their child's progress or more formally through parent-teacher interviews.

"Probably mostly how she's fitting in...there was a little bit of discussion as to, you know, sort of whereabouts she's at with her learning and what not." (Parent)

"If I had concerns I just speak to the parent. Yes I would do that outside of the normal school interview." (Teacher)

Parents tended to know less about their child's mathematical progress than they knew about their child's ability and progress in reading.

"The whole focus seems to be on reading and learning the letters and the sounds and I suddenly realised that, yeah, obviously they do some maths and counting and puzzles and things like that but you are not really aware of it and it doesn't seem to be anywhere near the emphasis on it that there is on the reading side of things."

"I guess we were sort of waiting for the school. I didn't want to push it ... I think there is not a lot of feedback between the teachers so to be honest with you I don't really know where she is at there."

“We had an initial report to say how well she had settled in and things, but we haven't had specifics, apart from reading. I always find this. You know how good your child is at reading but you never quite know how good they are at maths."

From the teacher interviews and from classroom observations, it became evident that within the classroom the teacher authorizes particularities relating to activities in time and space, and, importantly, regulating what is to count as mathematical provision. In creating particular modes of activity, ways of being and interpersonal relationships, such decision making makes possible both what can be said and what can be done within the new entrant classroom in relation to mathematics. 


\section{Conclusion}

Structural processes and practices make a significant contribution to the ways in which mathematics is understood in the two different sites. In Foucault's understanding, teachers and children think of mathematics in relation to the discourses of teaching and learning available within a specific context. What mathematics means within a Center is understood differently from within the setting of a new entrant classroom. Both settings have their own particular regime of truth which legitimizes and sanctions a discursive space for certain practices and social arrangements for mathematics provision. Each classroom produces its own truths about mathematical provision-truths which are not often shared between the two sectors (Anthony \& Walshaw, 2009). Thus mathematics provision in the two different settings becomes intelligible through its reliance on certain strategies that are accepted, sanctioned, and made to function as true with the different settings.

The ECE setting, through the knowledges and modes of operating that it advocated and promoted, had established a baseline understanding of mathematics provision. Through explicit engagements with the official curriculum statement for young learners, and its theoretical representations of development, pedagogy, assessment, and the learner, teachers understood what counted as evidence of mathematical provision. The teacher's role was to create a supportive learning environment, facilitating and empowering. Since all these "knowings" became the coordinates through which mathematics provision could be mapped, children came to know what particular mathematical knowledge was legitimated and the types of arrangements that were deemed central to facilitate that knowledge.

Practices that are at odds with each other across different educational sectors create a different sense of self and are most keenly felt by young learners as they transition across one educational setting to another. Transitioning from the ECE setting to the new entrant classroom, the young mathematics learner moves towards a different network of political and social practices. New discourses come into play and the positions and politics which these discourses offer, provide learners with access to a differential engagement and positioning in relation to mathematical knowledge. These discursive codes, and how they are to be taken up, are not always made explicit to the young learner. To the new entrant teacher, however, mathematics teaching and learning constituted a tight script that established how learning is to be enacted in the classroom. 
Thus, through a covert set of standards and value systems associated with mathematics provision, a different construction of the learner was naturalized and made inevitable. To that end, not only is the new entrant classroom a site for the regulation of mathematical provision, it is also a site of production and regulation of young learners in the mathematics classroom. Those practices are not necessarily the kind that the early childhood setting would wish to promote. The challenge is for more open communication channels between the early childhood and school settings. Bridging the early-years divide through cross-sector discussion and understanding might lead to more consistency and coherence in relation to the "regime of truth" about mathematics provision and lead to the construction of harmonious mathematical practices amongst young learners.

Each society has its regime of truth, its 'general politics' of truth: that is, the types of discourse which it accepts and makes function as true; the mechanisms and instances which enable one to distinguish true and false statements, the means by which each is sanctioned; the technique and procedures accorded value in the acquisition of truth; the status of those who are charged with saying what counts as true. (Foucault, 1984, p. 73)

\section{Acknowledgment}

The author wishes to thank Ngaire Davies and Karen Walker for their assistance in data collection for the project on which this paper is based.

\section{Note}

1. The decile rating of a school is based on a Government assessment of the school in terms of the nature of the school community, particularly regarding the predominant socioeconomic constitution of that community. A decile rating of 10 is the highest socioeconomically enriched. 


\section{References}

Anthony, G., \& Walshaw, M. (2009). Mathematics education in the early years: Building bridges. Contemporary Issues in Early Childhood, 10(2), 107-121.

Belcher, V. (2006). And my heart was thinking: Perceptions of new entrant children and their parents on transition to primary school numeracy. Unpublished master's thesis, University of Canterbury, New Zealand.

Carr, M. (2001). Assessment in early childhood settings. London: Paul Chapman.

Cobb, P., Gresalfi, M., \& Hodge, L. L. (2009). An interpretive scheme for analyzing identities that students develop in mathematics classrooms. Journal for Research in Mathematics Education, 40(1), 40-68.

Cullen. J. (2004). Adults co-constructing professional knowledge. In A. Anning, J. Cullen, \& M. Fleer (Eds.), Early childhood education: Society and culture (pp. 69-79). London: Sage Publications.

Davies, N. (2011). Supporting young children's mathematics learning as they transition to school. In J. Clark, B. Kissane, J. Mousley, T. Spencer, \& S. Thornton (Eds.), Mathematics: Tradition and [new] practices (Proceedings of the 34th annual conference of the Mathematics Education Research Group of Australasia and the 23rd biennial conference of the Australian Association of Mathematics Teachers, pp. 208-216). Alice Springs. Adelaide, SA: AAMT \& MERGA.

Davies, N., \& Walker, K. (2008). Explorations of early childhood-new entrant transitions in mathematics. In M. Goos, R. Brown, \& K. Makar (Eds.), Navigating currents and charting directions (Proceedings of the 31st annual conference of the Mathematics Education Research Group of Australasia, pp. 155-162). Brisbane, QLD: MERGA.

Foucault, M. (1972). The archaeology of knowledge and the discourse of language (Trans: A. Sheridan Smith). London: Pantheon.

Foucault, M. (1977). Discipline and punish. Harmondsworth: Penguin Books.

Foucault, M. (1984). The care of the self (Trans: R. Hurley, 1986). Harmondsworth: Penguin.
Jordan, B. (2004). Scaffolding learning and coconstructing understandings. In A. Anning, J. Cullen, \& M. Fleer (Eds.), Early childhood education: Society and culture (pp. 31-42). London: Sage Publications.

Kagan, S., \& Neuman, M. (1998). Lessons from three decades of transition history. Elementary School Journal, 98(4), 365-380.

Kienig, A. (2002). The importance of social adjustments for future success. In F. Fabian and A. Dunlop (Eds.), Transitions in the early years: Debating continuity and progression for young children in early education (pp. 23-37). London: RoutlegeFalmer.

Margetts, K. (2007). Understanding and supporting children: Shaping transition practices. In A-W. Dunlop \& H. Fabian (Eds.), Informing transition in the early years: Research, policy and practice (pp. 107-119). Berkshire: Open University Press.

Ministry of Education. (1996). Te Whäriki: The early childhood curriculum. Wellington: Learning Media.

Ministry of Education. (2001). Curriculum update, 45. Wellington: Learning Media.

National Council of Teachers of Mathematics. (2000). Principles and standards for school mathematics. Reston, VA: NCTM.

Neuman, M. (2002). The wider context. In F. Fabian \& A. Dunlop (Eds.), Transitions in the early years: Debating continuity and progression for young children in early education ( $\mathrm{pp}$. 8-22). London: RoutlegeFalmer.

Perry, B., \& Dockett, S. (2004). Mathematics in early childhood education. In B. Perry., G. Anthony, \& C. Diezmann (Eds.), Research in mathematics education in Australasia (pp. 103-125). Flaxton, QLD: Post Pressed.

Perry, B., \& Dockett, S. (2011). Playing with mathematics: Implications from the Early Years Learning Framework and the Australian Curriculum. In J. Clark, B Kissane, J. Mousley, T. Spencer, \& S. Thornton (Eds.), Mathematics: Tradition and [new] practices (Proceedings of the 34th annual conference of the Mathematics Education Research Group of Australasia and the 23rd biennial conference 
of the Australian Association of Mathematics Teachers, pp. 624-630). Alice Springs. Adelaide, SA: AAMT \& MERGA.

Peters, S. (2010). Literature review: Transition from early childhood education to school. New Zealand Ministry of Education. Retrieved from http://www.educationcounts.govt.nz/ publications.ece/78823.

Sherley, B., Clark, M., \& Higgins, J. (2008). School readiness: What do teachers expect of children's mathematics in school entry? In M. Goos, R. Brown, \& K. Makar (Eds.), Navigating currents and charting directions (Proceedings of the 31st annual conference of the Mathematics Education Research Group of Australasia, pp. 461-465). Brisbane, QLD: MERGA.
Stephenson, M., \& Parsons, M. (2007). Expectations: Effects of curriculum change as viewed by children, parents and practitioners. In A-W. Dunlop \& H. Fabian (Eds.), Informing transition in the early years: Research, policy and practice (pp. 137-148). Berkshire: Open University Press.

Timperley, H., McNaughton, S., Howie, L., \& Robinson, V. (2003). Transitioning from early childhood education to school: Teacher beliefs and transition practices. Australian Journal of Early Childhood, 28(2), 32-38.

Young-Loveridge, J. (2011). Assessing the mathematical thinking of young children in New Zealand: The initial years of school. Early Child Development and Care, 181(2), 267-276.

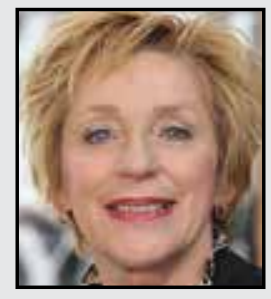

Margaret Walshaw is a Professor at Massey University, New Zealand. Her central research interest is in theories of the social and in linking these to educational contexts. She has published widely including articles in Review of Educational Research, Curriculum Inquiry, Contemporary Issues in Early Childhood, British Journal of Sociology of Education, and Journal for Research in Mathematics Education. 